\title{
Smart Ticketing System for Public Transport Vehicles
}

\author{
J. Subramaniyan ${ }^{\text {a, } 1}$, P.Senthil Kumar ${ }^{b}$, S. Sripriya ${ }^{b}$ \\ C. Jegan ${ }^{\mathrm{b}}$, M. Jenny ${ }^{\mathrm{b}}$ \\ ${ }^{a}$ Assistant Professor, Department of EEE, SRM TRP Engineering College, Trichy TN, \\ India \\ ${ }^{\mathrm{b}}$ Assistant Professor, Department of EEE, Roever Engineering College, Perambalur, \\ TN, India
}

\begin{abstract}
Recent Growth in technologies has taken drastic improvements in all fields especially public welfare. Soon transport systems with demanding technologies like frequency Identification Devices (RFID), GSM, and face recognition will gain the spotlight. The RFID concept is applied in a public transport identification card which is a reliable system, automatically detects the passenger, and the camera will recognize the passenger's face and debit the fare following the distance traveled. A feedback message is forwarded to the corresponding person's mobile, as a sign of good security. The security system is equipped with a GSM modem.IR sensor will count the persons entering and exiting the bus.
\end{abstract}

Keywords. GSM, RFID, IR Sensor

\section{Introduction}

Today, everything within the world is sensible and digitalized. Many advances are made within the transportation sector too. However, public conveyance buses in India have always been a neighborhood where such new advances have turned their faces out. Work Intelligent vehicle for conveyance is one among the research areas. Here global positioning system plays a crucial role to seek out positions. In certain urban areas, there could also be some errors to seek out the situation so an alternate approach may be a visual geometry [1-2]. In developing countries such as India, public transportation could be a significant source of revenue.

The ticket issuer faces various problems in issuing the tickets. Provided automatic issuing, the fare will be deducted corresponding to the distance traveled [3]. RFID technology is evolving in recent years. The proposed methodology includes a Contactless Fare Media Technology (CFMT) and an automatic money debiting system, as well as novel features, to bring India's public transportation bus system up to global standards [4]. The current ticketing system was riddled with flaws, malicious arguments among the general public, and corruption. It also intends to reduce farerelated fraud and revenue loss by utilizing open standard, secure transaction technology.

\footnotetext{
${ }^{1}$ J. Subramaniyan, Assistant Professor, Department of EEE, SRM TRP Engineering College, Trichy TN, India; E-mail: subramaniyan.j@trp.srmtrichy.edu.in.
} 
Nowadays the general public transportation just like the metro is well advanced. To improve the efficacy, existing public transportation is to be mutated towards intelligent transportation within the market [5].

The offline-based issuing system for receiving the fare is difficult to validate the acquisition of a ticket by every passenger. After the arrival of the destination, the hard copy of the ticket is useless. The number of unsold tickets per day is extremely high. In an era of advanced techno-communications, India needs to specialize in inculcating an automatic system for confiscating carfare.

The RFID-based ticketing system aims to provide a comfortable, stress-free, and straightforward mode of transportation while also facilitating the scaling of manpower. During this automated system, we replace the traditional ticket system with a sensible system that stores all of the user's data [6].

This is often almost like the ATM card. If people notify the continuation of a specific bus, the person can receive the tickets using the RFID technique, and by showing the ticket ahead of the bus, the door opens automatically and closes after some predetermined seconds. We will know the number of passengers and free spaces on the bus by using an LCD.

A ticket issuing system is primarily proposed to overcome the difficulty of exchanging tickets between two individuals in a traditional ticket system. Ticket friendly machines keep the fine print about the events provided by promoters so that customers can buy tickets in their accounts using smart cards [7].

Time and money are valuable when we try to find the simplest way to avoid problems. When travelling by bus without carrying cash, the proposed method requires only one identification card. Once the passenger inserts the open-end credit into the ticket friend machine, the RFID reader within the open-end credit contains pay mode terms, which check for the account's balance. Following the receipt of RFID data, the information about transportation facilities is transmitted via an enormous display [8].

The evaluation of human faces in images is referred to as face detection. It disregards other objects such as buildings, trees, and bodies. Face perception is a hot topic in the computer vision community right now [9]. In applications such as video surveillance, human-computer interface, face recognition, and image management, face localization and detection is usually the first step. Identifying a face could be a consideration for facial recognition or expression analysis. The Haar-Classifier is used for face tracing in this paper [10].

During this current period, numerous incidents such as robbery, theft, and unwelcome entry occur on an unanticipated basis. As a result, security is important in this lifestyle. People are always busy with their day-to-day tasks, but they also want to ensure the safety of their prized possessions.

They forget to search for important things like keys, wallets, credit cards, and so on. If they don't have these, they won't be able to get into their house or anywhere else. A key, a security password, an RFID card, or an ID card are all required to gain access to a conventional security system. These security devices, on the other hand, have vulnerabilities, such as being forgotten or stolen by unauthorized people [11-13].

As a result, there is a need to create applications that guarantees a higher degree of protection, which could be used as a model. Our brain can only think in pictures, not words, which is one of its defining characteristics. You might forget where you put your car key, but you'll never forget to bring a smile with you. Everyone has a distinct appearance that God has bestowed upon them. Since it can represent a person's feelings, the face is the most important part of our bodies. Physiological characteristics 
(face, fingerprint, finger geometry, hand geometry, palm, iris, ear, and so on) and behavioral parameters are the two forms of biometrics (signature, and keystroke attributes).

When you're sick, your behavioral parameters can change. A face detection and tracking device, in comparison to other biometrics, can be an easy and non-intrusive method. Face detection (1:1) and face recognition (1:2) will be the two categories of the device (1:2). (N:1). Face detection necessitates the separation of face and non-face regions, while face recognition necessitates the matching of a single face image with multiple images from the input image.

\section{Methodology}

The traditional issue of the ticket system for debiting the travel fare is a vital source of loss in revenue. It is difficult to check the reliability of a ticket by every passenger. This paper explores an automated card-driven system using RFID for bus journeys in India. PTS is currently experiencing severe malfunction and security issues. The main issue is that there are several misunderstandings among passengers regarding fares. Besides, a security crisis arises in PTS.

\section{$2.1 \quad$ Existing system}

Each bus is generally controlled by a conductor. The conductor takes money from each passenger and issues them a ticket. Initially, tickets are printed on paper or tokens. Nowadays, handloom machines are used to print tickets. The passenger must carry the ticket until the train arrives at its destination, the conductor must ensure that everyone has a ticket, the ticketing time is relatively long, and paper is required to print the ticket. As an example, suppose a passenger wishes to travel by bus. He should bring the cash with them. The conductor then collects the money and hands out the ticket. This must be repeated by all passengers. This results in more time and waste, as well as a drain on human resources and energy.

\subsection{Proposed system}

Nowadays the public transportation system like the metro is well advanced. The proposed system is shown in Figure 1. In this system, RFID comprises two parts, RFID Tagger, and Reader. RFID Tag contains data related to the user. RFID reader deduce the above information's from the passenger RFID Tag However face recognition is done by a camera that is implemented by haar cascade techniques. IR sensor counts the persons entering the bus and then the bus door will be opened with the help of a relay circuit. The distance will be analyzed using a proximity sensor. Whenever the passenger gets down from the bus IR sensor count will be decremented and the reader detects the tag again and then the door will be opened. The amount will be debited from the account automatically based on distance travelled. 


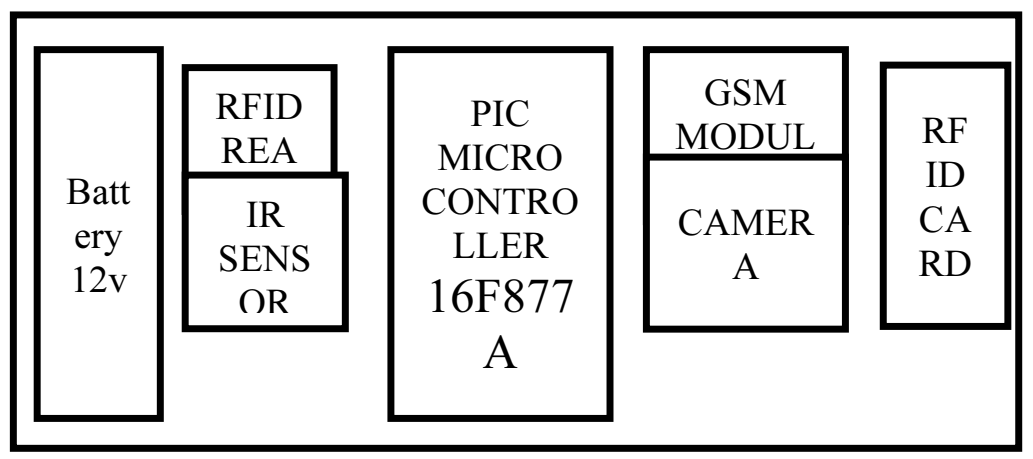

Figure 1. Proposed Block Diagram

\section{Result discussion}

An RFID-based fare collection system deployed as shown in Figure 2, could soon eliminate operating costs.

Authorities shall trace the vehicle in real-time which in turn reduce delays and thereby providing extra resources (buses or trains) to corresponding routes

The reader can communicate with the tag via radio waves. With the RFID smart card in his/her pocket, an individual can be detected and debited the appropriate amount.

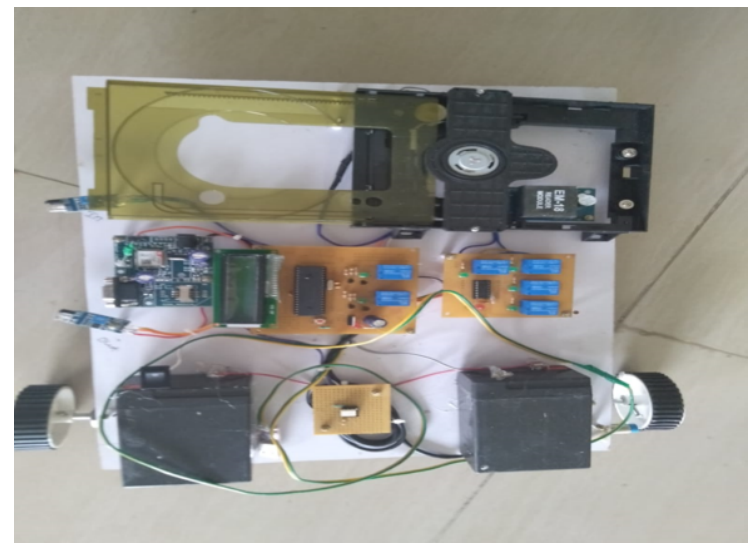

Figure 2. Smart Ticketing System

\section{Conclusion}

The working model focus on a hybrid energy generation technique where it combines solar system and vertical axis wind turbine system, The Generated power from all the renewable sources needs concentration on a better state of extraction of power without any distortion. We have proposed a Modified DC to DC converter topology for providing a ripple-free output. Future work on this extension may include detailed analysis of the selection of renewable power on season and availability along with a suitable controller. 


\section{References}

[1] Ravada, B. R., Tummuru, N. R., \& Ande, B. N. L. (2021). Photovoltaic-wind and hybrid energy storage integrated multi-source converter configuration for DC microgrid applications. IEEE Transactions on Sustainable Energy, 12(1), 83-91. https://doi.org/10.1109/TSTE.2020.2983985

[2] Sathe, A. D., \& Deshmukh, V. D. (2017). Advance vehicle-road interaction and vehicle monitoring system using smart phone applications. In Proceedings of 2016 Online International Conference on Green Engineering and Technologies, IC-GET 2016. Institute of Electrical and Electronics Engineers Inc. https://doi.org/10.1109/GET.2016.7916825

[3] Herdiyanto, D. W., Endroyono, \& Pratomo, I. (2017). Passenger authentication and payment system using RFID based on-board unit for Surabaya mass rapid transportation. In Proceeding - 2016 International Seminar on Intelligent Technology and Its Application, ISITIA 2016: Recent Trends in Intelligent Computational Technologies for Sustainable Energy (pp. 305-310). Institute of Electrical and Electronics Engineers Inc. https://doi.org/10.1109/ISITIA.2016.7828677

[4] Hargunani, K., Kengar, P., Lokhande, M., Gawade, R., \& More, S. K. (2018). Integrated Bus System Using QR Code. In Proceedings - 2018 4th International Conference on Computing, Communication Control and Automation, ICCUBEA 2018. Institute of Electrical and Electronics Engineers Inc. https://doi.org/10.1109/ICCUBEA.2018.8697591

[5] Akter, S., Islam, T., Olanrewaju, R. F., \& Binyamin, A. A. (2019). A Cloud-Based Bus Tracking System Based on Internet-of-Things Technology. In 2019 7th International Conference on Mechatronics Engineering, ICOM 2019. Institute of Electrical and Electronics Engineers Inc. https://doi.org/10.1109/ICOM47790.2019.8952037

[6] Harini, B. K., Parkavi, A., Supriya, M., Kruthika, B. C., \& Navya, K. M. (2020). Increasing Efficient Usage of Real-Time Public Transportation Using IOT, Cloud and Customized Mobile App. SN Computer Science, 1(3). https://doi.org/10.1007/s42979-020-00161-8

[7] J.Subramaniyan, S.Ajitha, A.Jothi, S.K.Nitharsini, Secured Disposal System, International Journal Of Information And Computing Science, 6 (2019), 639.

[8] J.Subramaniyan, V.Muthukumarasamy, V.Vengatesan, G.Ramprakash, Money Withdrawal from ATM By Using OTP with Secure Bio Metric JASC: Journal of Applied Science and Computations, 5(2018).

[9] Ganesh, S., Vengatesan, V., Richard Jimreeves, J., \& Ramasubramanian, B. (2020). Simultaneous network reconfiguration and pmu placement in the radial distribution system. Advances in Mathematics: Scientific Journal, 9(10), 8143-8151. https://doi.org/10.37418/amsj.9.10.44

[10] Ganesh, S., Ram Prakash, G., \& Michline Rupa, J. A. (2021). Optimal placement of green power generation in the radial distribution system using harmony search algorithm. In Advances in Intelligent Systems and Computing (Vol. 1167, pp. 245-252). Springer. https://doi.org/10.1007/978-981-15-52854_23

[11] Selvaraj, G., Thangaiyan, V., \& Rajangam, K. (2021). Numerical method for islanding the location of ground fault in the material based distribution system. Materials Today: Proceedings, 45, 634-639. https://doi.org/10.1016/j.matpr.2020.02.723

[12] Ganesh, S., \& Kanimozhi, R. (2018). Multi objective approach for capacitor placement based on load balancing index in radial distribution system. Journal of Computational and Theoretical Nanoscience, 15(1), 282-288. https://doi.org/10.1166/jctn.2018.7086

[13] Ganesh, S., \& Kanimozhi, R. (2018). Meta-heuristic technique for network reconfiguration in distribution system with photovoltaic and D-STATCOM. IET Generation, Transmission and Distribution, 12(20), 4524-4535. https://doi.org/10.1049/iet-gtd.2018.5629 